\title{
Do GOLD stages of COPD severity really correspond to differences in health status?
}

\author{
R. Antonelli-Incalzi*, C. Imperiale" ${ }^{\#}$ V. Bellia ${ }^{\Uparrow}$, F. Catalano ${ }^{\Uparrow}$ N. Scichilone ${ }^{\Uparrow}$, R. Pistelli*, F. Rengo ${ }^{+}$, \\ and the SaRA investigators
}

Do GOLD stages of COPD severity really correspond to differences in health status? R. Antonelli-Incalzi, C. Imperiale, V. Bellia, F. Catalano, N. Scichilone, R. Pistelli, F. Rengo, and the SaRA investigators. C) ERS Journals Ltd 2003.

ABSTRACT: The purpose of this study was to assess whether different stages of chronic obstructive pulmonary disease (COPD) severity defined according to the Global Initiative for Chronic Obstructive Lung Disease (GOLD) criteria correlate with meaningful differences in health status.

A total of 381 COPD patients, aged $73 \pm 6$ yrs, were classified in the five GOLD stages. Disease-specific (St George Respiratory Questionnaire (SGRQ)) and generic indexes of health status were measured in all patients. Multivariate analysis of covariance or Kruskal Wallis tests were used to compare health status indexes across the spectrum of GOLD stages of COPD severity.

GOLD stages of COPD severity significantly differed in SGRQ components and Barthel's index, but not in the indexes assessing cognitive and affective status and quality of sleep. The largest variation in health status was observed at the transition from stage IIa to stage IIb, while there were no other significant differences between consecutive stages. Both female sex and comorbidity were associated with a greater impact of COPD on the health status.

In conclusion, the upper limit of stage IIb (forced expiratory volume in one second of 49\%) marks a threshold for dramatic worsening of health status. Progression of chronic obstructive pulmonary disease severity from stage 0 to stage IIa does not correspond to any meaningful difference in health status.

Eur Respir J 2003; 22: 444-449.
*Institute of Internal Medicine and Geriatrics, Catholic University, Rome, " San Raffaele Cittadella della Carità Foundation, Taranto, "Institute of General Medicine and Pulmonology, University of Palermo, Palermo and ${ }^{+}$Institute of Internal Medicine and Geriatrics, Federico II University, Naples, Italy.

Correspondence: R. Antonelli-Incalzi, Dept of Geriatrics (CEMI), Università Cattolica, Largo A. Gemelli n. 8, 00168, Roma, Italy. E-mail: raffaele_antonelli@rm.unicatt.it Fax: 39063051911

Keywords: Chronic obstructive pulmonary disease, elderly, Global Initiative for Chronic Obstructive Lung Disease guidelines, health status

Received: November 52002

Accepted after revision: April 182003

The Salute Respiratoria nell'Anziano: Respiratory Health in the Elderly Study (SaRA) was supported by a research grant from Boehringer Ingelheim, Italy.
The Global Initiative for Chronic Obstructive Lung Disease (GOLD) has recently released a four-stage classification of chronic obstructive pulmonary disease (COPD) severity to guide the therapeutic approach [1]. In these patients, stage 0 defines the condition characterised by classic clinical symptoms but normal spirometry. Stage I defines patients with a forced expiratory volume in one second (FEV1)/forced vital capacity (FVC) of $<70 \%$, and an FEV1 of $>80 \%$ predicted, with or without chronic symptoms that may or may not be aware of disease status. Stage II (FEV1/FVC $<70 \%$, FEV1 $30-79 \%$ ) is split into substages IIa (FEV1 50-79\%) and IIb (FEV1 30-49\%) according to the greater rate of exacerbation experienced by patients in substage IIb, which in turn is inversely related to health status [2]. Finally, stage III (FEV1/ FVC $<70 \%$ and either FEV1 $<30 \%$ pred, hypoxaemia, or clinical signs of right heart failure) is expected to be associated with the worst health status.

However, the GOLD guidelines do not clearly define the rationale supporting the suggested classification scheme. Previous experience shows that worsening health status only reflects increased COPD severity categorised on the basis of FEV1 \% pred, to a limited extent. Instead, comorbidity plays an important role in defining health status, mainly in mild-tomoderate COPD [3]. The Salute Respiratoria nell'Anziano: Respiratory Health in the Elderly (SaRA) study provides a unique opportunity of verifying whether and to what extent GOLD stages of COPD severity correlate with health status.
The availability of disease-specific indexes of health status and of indexes of performance allows detection of the differences between stages. Thus, the present analysis has been performed to test the discriminatory capacity of the GOLD staging system versus health status.

\section{Methods}

A detailed description of the SaRA study is available elsewhere [4, 5]. Briefly, the SaRA study aims to define the relationship between disease severity and health status and its main determinants in a population aged $>64$ yrs with chronic respiratory problems. In the present study, 381 patients with a definite diagnosis of COPD or nonobstructive bronchitis were classified according to GOLD stages of COPD severity. A diagnosis of nonobstructive bronchitis, corresponding to GOLD stage 0 , was made if patients complained of cough and sputum for $\geqslant 3$ months $\cdot \mathrm{yr}^{-1}$ for $\geqslant 2$ yrs consecutively (Chemical Industries Barel (CIBA) criteria), but had normal spirometry.

Patients were considered to be affected by COPD if they fulfilled either of the following criteria: 1) they met the CIBA criteria, had an FEV1/FVC of $<70 \%$ pred and no change or an FEV1 increase of $>12 \%$, but not FEV1 normalisation after $100 \mu \mathrm{g}$ fenoterol; or 2) they neither met the CIBA criteria nor 
reported history of wheeze in the last year, had an FEV1/FVC of $<70 \%$ pred, an FEV1 of $<80 \%$ pred and an FEV1 increase of $<12 \%$ after $100 \mu \mathrm{g}$ fenoterol.

A diagnosis of asthma was made if patients did not meet the CIBA criteria and had either of the following: 1) an FEV1 of $>80 \%$ pred and a history of wheeze in the last year; 2) an FEV1 of $<80 \%$ pred, an FEV1 increase of $>12 \%$ after $100 \mu \mathrm{g}$ fenoterol and a history of wheeze in the last year; or 3) an FEV1 of $<80 \%$ pred, an FEV1 increase of $>12 \%$ after $100 \mu \mathrm{g}$ fenoterol and no history of wheeze in the last year. Asthmatics were excluded from the study.

Health status was measured using disease-specific indexes ("Symptoms", "Activity" and "Impacts" components and "Total" score of the St George Respiratory Questionnaire (SGRQ)) and generic indexes assessing cognitive performance (Mini Mental Status Examination (MMSE)), affective performance (15-item Geriatric Depression Scale (15-GDS)), physical performance (Barthel's index, 6-min walking test) and quality of sleep (index of disturbed sleep from the Established Populations for Epidemiologic Studies of the Elderly questionnaire (EPESE)), respectively [6-12]. The 6-min walking distance is expressed as per cent of the predicted based on age, sex, height and weight (WT \% pred) [13]. The meanings of individual indexes and information on their validity in older COPD patients are presented in table 1 .

Differences in health status indexes among groups were assessed as follows.

1) Multivariate analysis of covariance (MANCOVA) for indexes with both normal distribution and homogeneous variance: MMSE, WT \% pred, SGRQ Impacts, SGRQ Total, EPESE. The effects of three factors (GOLD stage, sex, living conditions (alone, with relatives/others)) and four covariates previously proven (waist:hip ratio, occiput-wall distance, number of comorbid diseases) or the likelihood of affecting the health status in COPD (age) were also assessed [3, 14]. The Wilk's lambda coefficient was computed to quantify the effects of individual factors and their effect on health status. The contribution of individual covariates toward an explanation of the distribution of the dependent variables was expressed by the respective $F$ value. For each dependent variable, a multiple regression versus all the covariates was also performed and the $\beta$ coefficient was assumed as a measure of the relationship between the dependent variable and the corresponding covariate. Post hoc differences between stages were assessed by the Scheffè test.

2) Kruskal Wallis test for indexes lacking normal distribution and/or homogeneous variance: 15-GDS, Barthel's index, SGRQ Symptoms and Activity. Differences between stages were assessed using the Mann-Whitney U-test.

The linear regression analysis was performed to assess the relationship between SGRQ Total and airway obstruction, as expressed by FEV1\%.

\section{Results}

The general characteristics of patients are summarised in table 2. A geriatric and poorly educated population was used in this study, a minority of which continued to smoke. About one in four patients was female and one in five lived alone. The average occiput-wall distance of $6.6 \mathrm{~cm}$ indirectly testifies that osteoporosis was a common problem. The average nutritional status expressed by the body mass index, was normal, whereas the relatively high waist:hip ratio was consistent with a prevalently visceral distribution of fat. Most of the drugs used were intended for nonrespiratory problems. Cardiovascular diseases, diabetes mellitus, visual and hearing impairment were the most common comorbid conditions.

The demographical characteristics and respiratory function indexes of patients grouped according to GOLD stages are reported in table 3. Stages had comparable age and proportion of patients living alone, whereas the prevalence of females was higher in stages 0-IIA. According to classification criteria, both FEV1 \% and FEV1/FVC were normal in GOLD stage 0 .

MANCOVA results are reported in table 4. Increasing

Table 1.-Indexes of health status measured in the Salute Respiratoria nell'Anziano: Respiratory Health in the Elderly study

\begin{tabular}{|c|c|c|c|}
\hline Index & Measure & Range of values & Validity in COPD \\
\hline \multicolumn{4}{|l|}{ SGRQ $^{\#}$} \\
\hline Symptoms & $\begin{array}{l}\text { Measures frequency and severity of } \\
\text { respiratory symptoms }\end{array}$ & $0-100^{\bullet}$ & $\begin{array}{l}\text { Designed for and validated } \\
\text { in COPD patients [6] }\end{array}$ \\
\hline Activity & $\begin{array}{l}\text { Assesses physical activities that either } \\
\text { cause or are limited by dyspnoea }\end{array}$ & $0-100^{\bullet}$ & \\
\hline Impacts & $\begin{array}{l}\text { Quantifies the impact of the respiratory } \\
\text { disease on daily life }\end{array}$ & $0-100^{\bullet}$ & \\
\hline Total & A summary measure of health status & $0-100^{\bullet}$ & \\
\hline 6-min walking test & $\begin{array}{l}\text { Can be considered as a measure of } \\
\text { sub-maxima physical performance }\end{array}$ & $\begin{array}{l}\text { Normal values can be } \\
\text { predicted on the basis of } \\
\text { age, sex, body and weight }\end{array}$ & $\begin{array}{l}\text { A highly reliable measure } \\
\text { in COPD [10] }\end{array}$ \\
\hline Barthel's index & $\begin{array}{l}\text { Measures the patient's independence } \\
\text { in self-care and mobility }\end{array}$ & $0-100^{+}$ & $\begin{array}{l}\text { Proved to be highly correlated } \\
\text { with disease-specific measure } \\
\text { of health status in COPD [14] }\end{array}$ \\
\hline MMSE & Commonly used to screen dementia & $\begin{array}{c}\quad 0-30 \\
\text { Abnormal values: MMSE }<24\end{array}$ & $\begin{array}{l}\text { The most reliable screening } \\
\text { instrument in older adults }[7,12]\end{array}$ \\
\hline 15-GDS & Largely used to screen depression & $\begin{array}{c}0-15 \\
\text { Abnormal values }>5\end{array}$ & $\begin{array}{l}\text { Proved to be valid in a } \\
\text { variety of settings [8] }\end{array}$ \\
\hline $\begin{array}{l}\text { EPESE index of } \\
\text { disturbed sleep }\end{array}$ & $\begin{array}{l}\text { Classifies four types of sleep } \\
\text { disturbances: difficulty initiating sleep; } \\
\text { waking at night; feeling of tiredness after } \\
\text { waking in the morning; waking too early }\end{array}$ & $0-16^{\S}$ & $\begin{array}{l}\text { Validity proved in older home- } \\
\text { dwelling subjects with chronic } \\
\text { diseases including COPD [11] }\end{array}$ \\
\hline
\end{tabular}

COPD: chronic obstructive pulmonary disease; SGRQ: St George Respiratory Questionnaire; MMSE: Mini Mental Status Examination; 15-GDS: 15-item Geriatric Depression Scale; EPESE: Established Populations for Epidemiologic Studies of the Elderly questionnaire. ${ }^{\#}$ : all disease-specific indexes of health status; ${ }^{\uparrow}: 0=$ no impairment, $100=$ maximal impairment; ${ }^{+}: 0=$ complete dependency, $100=$ complete independence; $^{\$}$ : $0=$ normal sleep, $16=$ maximally disturbed sleep. 
Table 2.-General characteristics of the patients

\section{Characteristics}

Females

Age yrs

Education $>8$ yrs

Living alone

Occiput-wall distance $\mathrm{cm}$

Waist:hip ratio

Body mass index $\mathrm{kg} \cdot \mathrm{cm}^{-2}$

Daily used drugs

Daily used respiratory drugs

Current smokers

Main comorbid diseases

Hypertension

Ischaemic heart disease

Diabetes mellitus

Visual impairment

Hearing loss

Congestive heart failure II NYHA class

Prostatic hypertrophy ${ }^{\#}$

Cerebrovascular disease

Tumours

Peptic ulcer

Parkinson's disease

Data are presented as $\mathrm{n}(\%)$ or mean \pm SD. NYHA: New York Heart Association. ${ }^{\#}$ : of male patients.

Table 3.-Demographical and respiratory function characteristics of patients grouped according to Global Initiative for Chronic Obstructive Lung Disease (GOLD) staging

\begin{tabular}{lccccc}
\hline & \multicolumn{5}{c}{ GOLD stage } \\
\cline { 2 - 6 } & 0 & I & IIa & IIb & III \\
\hline Age yrs & $74 \pm 7$ & $74 \pm 5$ & $73 \pm 5$ & $72 \pm 5$ & $73 \pm 6$ \\
Females $^{*}$ & $29 / 89$ & $12 / 48$ & $28 / 129$ & $9 / 89$ & $3 / 26$ \\
Living alone $^{+}$ & $24 / 87$ & $9 / 48$ & $27 / 124$ & $24 / 88$ & $8 / 26$ \\
FEV1 $^{+}$ & $92.3 \pm 23.5$ & $89.8 \pm 9.3$ & $63.7 \pm 8.5$ & $40 \pm 5.7$ & $26.2 \pm 2.8$ \\
FEV1/FVC $^{+}$ & $78 \pm 6.4$ & $63 \pm 4.6$ & $56.7 \pm 7.9$ & $41.4 \pm 9$ & $36.7 \pm 11.6$ \\
\hline
\end{tabular}

Data are presented as mean \pm SD or $\%$. FEV1: forced expiratory volume in one second; FVC: forced vital capacity. ${ }^{\#}$ : Chi-squared 15.3, p=0.005; : $\mathrm{F}=275, \mathrm{p}<0.001 ;^{+}: \mathrm{F}=295, \mathrm{p}<0.001$.

GOLD stage was associated with a dramatic worsening of health status (Wilk's lambda 0.85, p<0.001), as reflected by the SGRQ Impacts and Total, but not by MMSE, WT \% pred and EPESE. Female sex was also associated with greater scores in sleep, SGRQ Impacts and Total, i.e. with poorer quality of sleep and worse disease-specific health status (table 5). The interaction between living conditions (alone) and sex (female) (Wilk's lambda for interaction 0.95, $\mathrm{p}=0.02$ ) but not living alone per se (Wilk's lambda 0.96, $\mathrm{p}=0.054$ ) was associated with worse health status. No interaction between sex and GOLD stage was recorded. Comorbidity ( $F=2.66$, $\mathrm{p}=0.02)$ and age $(\mathrm{F}=2.33, \mathrm{p}=0.05)$, but not the occiput-wall distance $(\mathrm{F}=0.65, \mathrm{p}=0.66)$ and waist:hip ratio $(\mathrm{F}=1.15, \mathrm{p}=0.33)$, contributed to determining the distribution of the dependent variables.

Comorbidity was associated with a higher EPESE score, i.e. with worse quality of sleep $(\beta=0.175, \mathrm{p}<0.01)$ and higher Impacts $(\beta=0.137, p=0.02)$ and Total $(\beta=0.115, p=0.05)$ SGRQ scores. Age was associated with higher Total SGRQ score $(\beta=0.136, \mathrm{p}=0.02)$.

Post-hoc analysis of differences between GOLD stages showed important differences in both SGRQ Impacts and
Table 4.-Distribution of health status indexes by Global Initiative for Chronic Obstructive Lung Disease (GOLD) stages and sex, as assessed by multivariate analysis of covariance

\begin{tabular}{lcccccc}
\hline \multirow{2}{*}{ Index } & \multicolumn{5}{c}{ GOLD stage } & \multirow{2}{*}{ p-value } \\
\cline { 2 - 6 } & 0 & I & IIa & IIb & III & \\
\hline Subjects n & 89 & 48 & 129 & 89 & 26 & \\
SGRQ Impacts & $11 \pm 11$ & $11 \pm 10$ & $14 \pm 10$ & $21 \pm 11$ & $26 \pm 12$ & $<0.001$ \\
SGRQ Total & $30 \pm 22$ & $36 \pm 19$ & $38 \pm 20$ & $50 \pm 16$ & $62 \pm 17$ & $<0.001$ \\
MMSE & $26 \pm 3$ & $26 \pm 3$ & $25 \pm 3$ & $26 \pm 4$ & $26 \pm 3$ & 0.75 \\
EPESE & $4 \pm 4$ & $4 \pm 4$ & $3 \pm 4$ & $4 \pm 4$ & $3 \pm 4$ & 0.06 \\
6-min WT \% pred & $78 \pm 27$ & $75 \pm 26$ & $72 \pm 27$ & $61 \pm 27$ & $59 \pm 22$ & 0.07 \\
\hline
\end{tabular}

Data are presented as mean \pm SD unless otherwise stated. Significant $(\mathrm{p}<0.01)$ differences between GOLD stages were as follows. St George Respiratory Questionnaire (SGRQ) Impacts and Total: 0-IIb, 0-III, IIIb, I-III, IIa-IIb, IIa-III; 6-min walk distance (6-min WT) \% predicted; 0-IIb. MMSE: Mini Mental Status Examination; EPESE: Established Populations for Epidemiologic Studies of the Elderly questionnaire.

Table 5.-Distribution of health status indexes by sex, as assessed by multivariate analysis of covariance

\begin{tabular}{lccc}
\hline Index & Females & Males & p-value \\
\hline SGRQ Impacts & $47 \pm 14$ & $39 \pm 11$ & 0.03 \\
SGRQ Total & $21 \pm 24$ & $16 \pm 21$ & 0.01 \\
MMSE & $27 \pm 2.2$ & $26 \pm 2.8$ & 0.57 \\
EPESE & $6.3 \pm 4.2$ & $3.2 \pm 4.2$ & $<0.001$ \\
6-min WT \% pred & $72 \pm 27$ & $68 \pm 27$ & 0.49 \\
\hline
\end{tabular}

Data are presented as mean \pm SD unless otherwise stated. SGRQ: St George Respiratory Questionnaire; MMSE: Mini Mental Status Examination; EPESE: Established Populations Epidemiologic Studies of the Elderly questionnaire; 6-min WT \% pred: 6-min walked distance expressed as a per cent of the predicted.

Total between nonconsecutive stages but only between IIa and IIb consecutive stages.

The differences among GOLD stages in health status indexes assessed by the Kruskal Wallis test are reported in table 6. Both SGRQ Symptoms and Impacts worsened from stage 0 to stage III, but the only consecutive stages significantly differing in these indexes were IIa and III. Variability in health status scores was very high: $23 \%$ of stage 0 and $25.5 \%$ of stage I patients scored $>64$, which correspond to the average score of patients in stage IIb, on the SGRQ Symptoms.

Table 6.-Distribution of health status indexes by Global Initiative for Chronic Obstructive Lung Disease (GOLD) stages, as assessed by the Kruskal Wallis test

\begin{tabular}{lcccccc}
\hline Index & \multicolumn{5}{c}{ GOLD stage } & \multirow{2}{*}{ p-value } \\
\cline { 2 - 6 } & 0 & I & IIa & IIb & III & \\
\hline Subjects n & 89 & 48 & 129 & 89 & 26 & \\
SGRQ Symptoms & $40 \pm 26$ & $44 \pm 22$ & $47 \pm 24$ & $64 \pm 17$ & $60 \pm 21$ & $<0.001$ \\
SGRQ Activity & $38 \pm 27$ & $41 \pm 22$ & $49 \pm 26$ & $65 \pm 19$ & $72 \pm 16$ & $<0.001$ \\
Barthel's index & $98 \pm 4$ & $98 \pm 5$ & $96 \pm 7$ & $94 \pm 4$ & $91 \pm 10$ & $<0.001$ \\
15-GDS & $5 \pm 4$ & $4 \pm 3$ & $3 \pm 3$ & $4 \pm 3$ & $5 \pm 3$ & 0.055
\end{tabular}

Data are presented as mean \pm SD unless otherwise stated. Significant $(\mathrm{p}<0.01)$ differences between GOLD stages were as follows. St George Respiratory Questionnaire (SGRQ) Symptoms: 0-IIb, 0-III, I-IIb, IIa-IIb; SGRQ Activity: 0-IIa, 0-IIb, 0-III, I-IIb, I-III, IIa-IIb, IIaIII; Barthel's index: 0-IIb, 0-III, I-IIb, I-III, IIa-III; 15-GDS: 15-item Geriatric Depression Scale. 


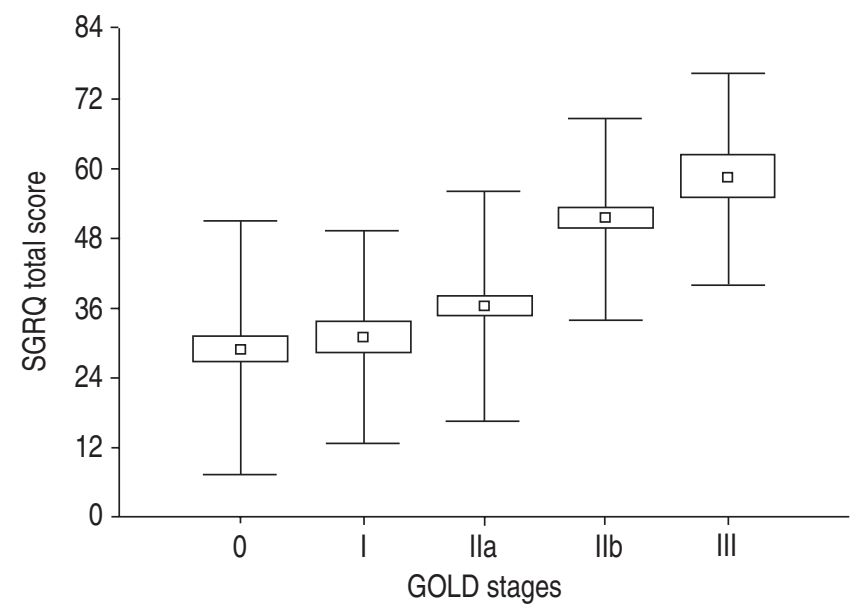

Fig. 1.-Box plot showing the distribution of St George Respiratory Questionnaire (SGRQ) scores by Global Initiative for Chronic Obstructive Lung Disease (GOLD) stage. Numbers on the y-axis show the minimal clinically significant difference. Error bars show $\mathrm{SD}$, small boxes show the mean and larger boxes show the SE.

Figure 1 is a box plot showing the distribution of SGRQ scores by GOLD stage. Clinically significant differences, i.e. of a magnitude of $>4$, in the average value (or median) were observed between all consecutive stages with the exception of $0-$ I. A consistent overlap of recorded values among stages 0 , I and IIa as well as between stages IIb and III is also evident.

The linear regression analysis yielded the following equation:

$$
\text { SGRQ Total }=64.603-0.3885 \mathrm{FEV}_{1} \%
$$

Where $\mathrm{R}=-0.4605$ and $\mathrm{R}^{2}=0.212$. Thus, the severity of airway obstruction explains only one fifth of the observed variance in health status, as reflected by the SGRQ Total.

\section{Discussion}

The present results demonstrate that the GOLD staging system marks important differences in health status assessed by a disease-specific index or the Barthel index. The age of the patients may explain why the Barthel's index but not the WT $\%$ pred could distinguish between groups, as the elderly are exposed to the negative impact of disabling conditions mainly on the basic and instrumental activities of daily living. Accordingly, a test assessing submaximal physical performance is expected to lose part of its discriminatory capacity in an elderly population. Indexes of affective status and quality of sleep could not distinguish GOLD stages, although depression and disturbed sleep are common COPD-related problems. Indeed, depression and sleep problems seem to complicate COPD in its earliest stage but, at variance from physical limitations, their prevalence and severity do not parallel increasing COPD severity. The relatively low size of the stage III population, i.e. of patients most exposed to the risk of cognitive impairment, may explain why MMSE also failed to distinguish GOLD stages.

The present findings have been obtained in a rigorously selected population and corrected for the confounding effect of several variables proven or supposed to affect the health status. Thus, they demonstrate that GOLD staging of COPD corresponds to important differences in health status between stages IIa and IIb, but not between other consecutive stages. This suggests that the boundary between stages IIa and IIb marks a turning point in the evolution of health status in
COPD patients. In contrast, no significant change in health status marks the earliest progression of COPD from stage 0 to I and from I to IIa, as well as its ultimate transition from stage IIb to III. The size inequality of groups IIb and III and the consistent overlapping of health status scores recorded in consecutive stages are likely to explain these findings.

An index of airway obstruction accounted for a minority of the explained variance in SGRQ Total score. This finding and the great interindividual variability in health status within a given GOLD stage clearly shows that health status cannot be inferred from the GOLD stage and should be systematically assessed in the individual patient. It would appear that a disease-specific instrument is recommended due to its superior discriminatory capacity. However, a generic index of physical capability, such as the Barthel's index, can represent a valuable alternative because it requires very little time and allows comparison between patients with different main diseases.

The observed greater susceptibility of females to the negative effects of COPD on the health status represents an original finding. Indeed, the authors could find only one report showing that female sex weakens the positive effects of rehabilitation on disease-related health status in COPD [15]. A similar sex effect has been reported for cardiovascular rehabilitation programmes [16]. Whatever its determinants, the observed phenomenon deserves special consideration. Indeed, females represent a rapidly increasing proportion of all COPD patients, as can be inferred from the dramatically rising prevalence of cigarette smoking among females, as well as from the greater impact of smoke on lung function of females [17, 18]. Furthermore, COPD will become the fifth leading cause of disability in affluent countries by year 2020 [19]. The dramatic rise in the prevalence of female patients is hypothesised to result in a greater than expected effect of COPD on the health status and, as a consequence, the need of care.

Patients classified in the 0 and I GOLD stages have an FEV1 of $>80 \%$ pred and, thus, are excluded from previous classifications of COPD severity [20-22]. This prevents any comparison of health status classifications achieved by GOLD and previous staging systems. Nevertheless, the finding that about one of four patients in GOLD stage 0 scored higher than the average patient in GOLD stage IIb suggests that health status frequently deteriorates even in the absence of bronchial obstruction, possibly because of respiratory symptoms or coexisting nonrespiratory problems. The impact of comorbidity on selected measures of health status in this and in a previous study supports the latter hypothesis [3].

The limitations of this study deserve to be discussed. First, survival bias might have attenuated the differences between the most severe stages. Only a longitudinal study can test this hypothesis. Secondly, the lack of statistically significant differences between consecutive stages other than IIa and IIb does not guarantee that clinically significant differences were absent. Indeed, stages I and IIa, as well as stages IIb and III, differed in SGRQ Total score by six and 12 points, respectively, i.e. of a magnitude well over the clinically relevant minimal difference of four [6]. These differences might qualify as statistically significant in a larger population. Finally, distinguishing long-standing asthma from COPD is quite problematic in the elderly [23]. The authors' diagnostic criteria were carefully developed and rigorously applied but could not guarantee the absence of occasional misclassifications.

In conclusion, findings from this study show that staging chronic obstructive pulmonary disease according to Global Initiative for Chronic Obstructive Lung Disease guidelines does correspond to important differences in health status, but 
that health status patterns of consecutive stages overlap remarkably. Further research is needed to verify whether integrating the Global Initiative for Chronic Obstructive Lung Disease stage with selected measures of health status will allow definition of subgroups with a distinctive prognosis. Special attention should be paid to the heterogeneity of health status in stages 0 and 1: selected health status patterns might be a marker of chronic obstructive pulmonary disease progression rate. Prospectively assessing these topics will improve knowledge of the Global Initiative for Chronic Obstructive Lung Disease classificatory and prognostic implications, as well as of the feasibility of a mixed, i.e. physiopathologicalclinical and health-status indicator based, chronic obstructive pulmonary disease staging system. Finally, the important differences in health status between stages IIa and IIb and the lack of significant differences between lower grade consecutive stages suggests that every effort should be made to prevent the progression of chronic obstructive pulmonary disease, since passing the boundary of a forced expiratory volume in one second of $<50 \%$ of predicted is likely to herald a dramatic decline of the health status.

Acknowledgements. All participants are indebted to G. Torresin and to the staff of Biomedin (Padua, Italy) for continuous and dedicated technical assistance.

SaRA Scientific Committee members. Napoli: F. Rengo (Coordinator); Palermo: V. Bellia (Coordinator); Brescia: V. Grassi; Florence: G. Masotti; Padua: S. Maggi; Parma: D. Olivieri; Naples: G. Melillo; Rome: R. Antonelli-Incalzi, M. Palleschi, R. Pistelli, M. Trabucchi, S. Zuccaro.

List of participating centres, principal investigator and associated investigators (the latter in brackets). Divisione di Medicina 1, Osp. Geriatrico INRCA, Ancona; D.L. Consales (P. Paggi, D. Lo Nardo). Divisione di Geriatria, Osp. Civile, Asti; F. Goria, P. Fea, (G. Iraldi, R. Corradi). Cattedra di Gerontologia e Geriatria, University of Bari; A. Capurso (R. Flora, F. Torres, G. Venezia, M. Mesto, R. Valerio, R. Noya, G. Argentieri). $5^{\circ}$ Divisione di Geriatria, Osp. Malpighi, Bologna; S. Semeraro (L. Bellotti, A. Tansella). Istituto di Medicina Interna, University of Brescia; V. Grassi (S. Cossi, G. Guerini, C. Fantoni, M. De Martinis, L. Pini, V. Pinelli). Divisione di Pneumologia, Fondazione "E. Maugeri", Telese (BN); G. Melillo (R. Battiloro, C. Gaudiosi, S. De Angelis). Istituto di Medicina Interna e Geriatria, University of Catania; L. Motta, D. Mugeri (I. Alessandria, S. Savia). Cattedra di Geriatria, University of Florence; G. Masotti (M. Chiarlone, D. Matteuzzi, S. Zacchei). Divisione di Geriatria, Osp. Morgagni, Forlì; V. Pedone (D. Angelini, D. Cilla). Divisione di Geriatria, Osp. Galliera, Genova; E. Palummeri (D. Torriglia, M. Agretti, P. Costelli, A. Giusti). Divisione di Geriatria, Osp. Richiedei, Gussago (Brescia); M. Trabucchi (P. Ranieri, F. Guerini, P. Barbisoni, P. Calabrese). Divisione di Geriatria, Osp. Generale, L'Aquila; F. Caione (D. Caione, M. La Chiara). I Div. Geriatria, Osp. San Gerardo, Monza; G. Galetti (A. Cantatore, D. Casarotti, G. Anni, B. Grumelli). Cattedra di Gerontologia e Geriatria, Federico II University of Naples; F. Rengo (F. Cacciatore, A.I. Pisacreta, C. Calabrese, V. Carnevale, P. Abete). Clinica geriatria, University of Padua, Padova; G. Enzi (S. Peruzza, P. Dalla Montà, P. Albanese, F. Tiozzo). Istituto di Malattie Apparato Respiratorio, University of Parma; D. Olivieri (V. Bocchino, A. Comel, N. Barbarito, M. Barbera). Cattedra di Gerontologia e Geriatria, University of Perugia; U. Senin (S. Peretti,
F. Arnone, L. Camilli). Divisione di Geriatria, Osp. Israelitico, Roma; S.M. Zuccaro (M. Marchetti, L. Palleschi). Divisione di Geriatria $1^{\circ}$, Osp. Gen. Addolorata, Roma; M. Palleschi (C. Cieri, F. Vetta). Istituto di Medicina Interna e Geriatria, Catholic University of Rome; P.U. Carbonin (F. Pagano, P. Ranieri, C. Romano). Istituto i Medicina Interna e Geriatria, University of Siena; S. Forconi (G. Abate, G. Marotta, E. Pagni). Fondazione San Raffaele, Cittadella della Carità, Taranto; R. Antonelli-Incalzi (C. Imperiale, C. Spada). Cattedra di Gerontologia e Geriatria, University of Milan, Milano; C. Vergani (M.C. Sandrini, G. Giardini, I. Dallera). Cattedra di Malattie dell'Apparato Respiratorio, Istituto di Medicina Generale e Pneumologia, University of Palermo; V. Bellia (F. Catalano, N. Scichilone, S. Battaglia, F. Tartamella).

Coordinating centre: Cattedra di Malattie dell'Apparato Respiratorio, Istituto di Medicina Generale e Pneumologia, University of Palermo; V. Bellia (F. Catalano, N. Scichilone, S. Battaglia, F. Tartamella).

\section{References}

1. Pauwells RA, Buist S, Calverley PMA, Jenkins CR, Hurd SS and the GOLD Scientific Committee (NHLBI-WHO workshop summary). Global strategy for the diagnosis, management, and prevention of chronic obstructive disease. Am J Respir Crit Care Med 2001; 163: 1256-1276.

2. Seemungal TA, Donaldson GC, Paul EA, Bestall JC, Jeffries DJ, Wedzicha JA. Effect of exacerbation on quality of life in patients with chronic obstructive pulmonary disease. $A m J$ Respir Crit Care Med 1998; 157: 1418-1422.

3. Ferrer M, Alonso J, Morera J, et al. Chronic obstructive pulmonary disease stage and health-related quality of life. Ann Intern Med 1997; 127: 1072-1079.

4. Bellia V, Pistelli R, Catalano F, et al. Quality control of spirometry in the elderly: the SA.RA. Study. Am J Respir Crit Care Med 2000; 161: 1094-1100.

5. Antonelli-Incalzi RA, Bellia V, Maggi S, et al. Reversible bronchial obstruction and disease-related health status in COPD. Qual Life Res 2002; 11: 517-525.

6. Jones PW, Quirk FH, Bavestock CM, Littlejohns P. A selfcomplete measure of health status for chronic airflow limitation. Am Rev Respir Dis 1992; 145: 1321-1327.

7. Folstein M, Folstein S, McHugh P. Mini mental state: a practical method for grading the cognitive state of patients for the clinician. J Psychiatr Res 1975; 12: 189-198.

8. Burke WJ, Roccaforte WH, Wengel SP. The short form of the Geriatric Depression Scale: a comparison with the 30item form. J Geriatr Psychiatry Neurol 1991; 4: 173-178.

9. Mahoney F, Barthel D. Functional evaluation: the Barthel Index. MD State Med $J$ 1965; 14: 61-65.

10. Guyatt GH, Sullivan MJ, Thompson PJ, et al. The six minute walk: a new measure of exercise capacity in patients with chronic heart failure. Can Med Assoc J 1985; 132: 919923.

11. Maggi S, Langlois JA, Minicuci N, et al. Sleep complaints in community-dwelling older person: prevalence, associated factors, and reported causes. J Am Geriatr Soc 1998; 46: $161-168$.

12. Jones RN, Gallo JJ. Dimensions of the Mini Mental State Examination among community dwelling older adults. Psychol Med 2000; 30: 605-618.

13. Enright PL, Sherrill DL. Reference equations for the sixminute walk in healthy adults. Am J Respir Crit Care Med 1998; 158: 1384-1387.

14. Antonelli-Incalzi RA, Bellia V, Catalano F, et al. Evaluation of health outcomes in elderly patients with asthma and COPD using disease-specific and generic instruments. The 
Salute Respiratoria nell'Anziano (Sa.R.A.) Study. Chest 2001; 120: 734-742.

15. Foy CG, Rejeski J, Berrjy MJ, Zaccaro D, Woodard M. Gender moderates the effects of exercise therapy on health-related quality of life among COPD patients. Chest 2001; 119: 70-76

16. Carhart RL Jr, Ades PA. Gender differences in cardiac rehabilitation. Cardiol Clin 1998; 16: 37-43.

17. Kanner RE, Connett JE, Altose MD, et al. Gender difference in airway hyperresponsiveness in smokers with mild COPD: the Lung Health Study. Am J Respir Crit Care Med 1994; 150: 956-961.

18. Prescott B, Bjerg AM, Andersen PK, Lange P, Vestbo J. Gender difference in smoking effects on lung function and risk of hospitalization for COPD: results from a Danish longitudinal population study. Eur Respir J 1998; 11: 792793.

19. Murray CJL, Lopez AD. Alternative projections of mortality and disability by cause 1990-2020: Global Burden of Disease Study. Lancet 1997; 349: 1498-1504.

20. American Thoracic Society. Standards for the diagnosis and care of patients with chronic obstructive pulmonary disease. Am J Respir Crit Care Med 1995; 152: Suppl. 5, s77s121.

21. The COPD Guidelines Group of the Standards of Care Committee of the BTS. BTS guidelines for the management of chronic obstructive pulmonary disease. Thorax 1997; 52: Suppl. 5, s1-s28.

22. Siafakas NM, Vermeire $\mathrm{P}$, Pride $\mathrm{NB}$, et al. Optimal assessment and management of chronic obstructive pulmonary disease (COPD). The European Respiratory Society Task Force. Eur Respir J 1995; 8: 1398-1420.

23. Braman SS, Kaemmerlen JT, Davis SM. Asthma in the elderly. A comparison between patients with recently acquired and long-standing disease. Am Rev Respir Dis 1991; 143: 336-340. 